\title{
Synchronized peak-rate years of global resources use
}

\author{
Ralf Seppelt $^{1,2,3}, \underline{\text { Ameur M. Manceur }}^{1,4}, \underline{\text { Jianguo Liu }}^{5}$, Eli P. Fenichel $^{6}$ and Stefan Klotz $^{2,7}$
}

\begin{abstract}
Many separate studies have estimated the year of peak, or maximum, rate of using an individual resource such as oil. However, no study has estimated the year of peak rate for multiple resources and investigated the relationships among them. We exploit time series on the appropriation of 27 global renewable and nonrenewable resources. We found 21 resources experienced a peak-rate year, and for 20 resources the peak-rate years occurred between 1960-2010, a narrow time window in the long human history. Whereas 4 of 7 nonrenewable resources show no peak-rate year, conversion to cropland and 18 of the 20 renewable resources have passed their peak rate of appropriation. To test the hypothesis that peak-rate years are synchronized, i.e., occur at approximately the same time, we analyzed 20 statistically independent time series of resources, of which 16 presented a peak-rate year centered on 2006 (1989-2008). We discuss potential causal mechanisms including change in demand, innovation and adaptation, interdependent use of resources, physical limitation, and simultaneous scarcity. The synchrony of peak-rate years of multiple resources poses a greater adaptation challenge for society than previously recognized, suggesting the need for a paradigm shift in resource use toward a sustainable path in the Anthropocene.
\end{abstract}

Key Words: limits to growth; peak-rate year; synchrony

\section{INTRODUCTION}

Sustainable appropriation of nonrenewable and renewable resources is required for society's long-term well-being. Four decades ago, Meadows' limits to growth model reignited the old Malthusian debate about the limits of the world's resources (Mathus 1798, Bardi 2000, Griggs et al. 2013). Limits to growth of specific resources such as oil (Hallock et al. 2014) or fossil water (Gleick and Palaniappan 2010) have been analyzed separately, by estimating the peak-rate, or maximum, year, defined as the year of maximum resource appropriation rate. For which renewable and nonrenewable resources can a peak-rate year be identified given the most up-to-date time series of human resource appropriation? Exploring the relation among peak-rate years for multiple resources then raises an important second question: are global peak-rate years synchronized, i.e., occurring at approximately the same time in the long history of human civilization? Calculating the appropriation rate of resources allows the detection of the maximum increase year or peak-rate year, which indicates the timing of scarcity or change in demand (Fig. 1). We analyzed peak-rate years for many of the world's major resources and found synchrony in the peak-rate years of statistically independent resources by a method that is standardized, nonparametric, generalizable, and allows analysis of nonrenewable and renewable resources (Table 1), and we will conclude by giving clear implications for sustainable development goals (Arrow et al. 1995).

We focused on 27 nonrenewable and renewable resources essential for human well-being and daily needs, e.g., energy and food. These resources are also the focus of global policy bodies such as the United Nations and the World Bank. Nonrenewables include the fossil fuels, i.e., coal, gas, oil, supplying $87 \%$ of the energy consumed by the 50 wealthiest nations (Tollefson and Monastersky 2012). Renewables include staple crops, e.g., cassava, maize, rice, soybeans, and wheat, which the Food and Agriculture Organization of the United Nations identified as providing $45 \%$ of global caloric intake (FAO 2013). Combined

Fig. 1. Conceptually, the peak-rate year of resource use is the point in time with the maximum appropriation rate (blue line). The appropriation of an individual resource proceeds through three phases. Initially, the resource is discovered and its use developed. Then, the resource is broadly used. Finally the resource is less accessible or scarce and substitutes are explored. The three phases may overlap over time. We analyzed renewable resources (regeneration at human life scale) and nonrenewable resources (regeneration on geologic time scale). For drivers of resource use, the peak-rate year is the year of maximum growth rate.

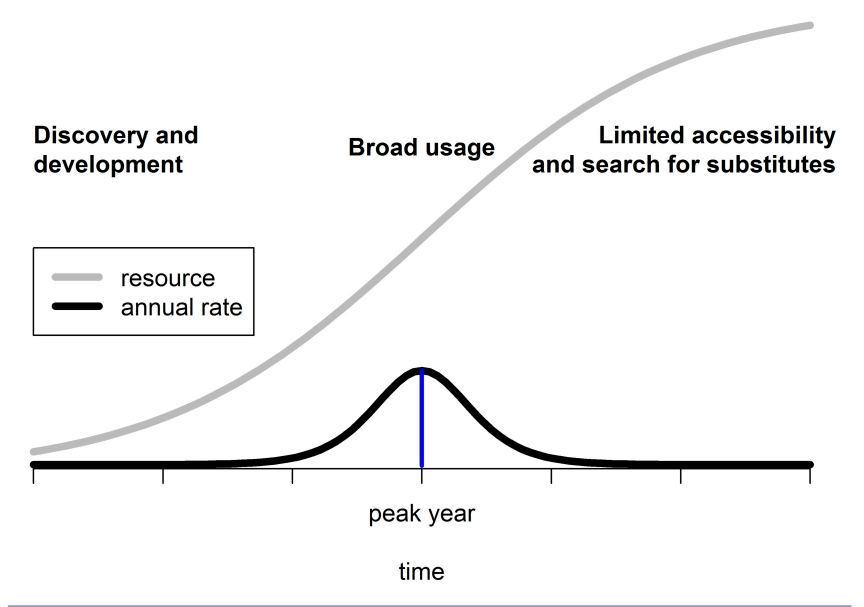

${ }^{1}$ UFZ - Helmholtz Centre for Environmental Research, Department Computational Landscape Ecology, ${ }^{2}$ iDiv - German Centre for Integrative Biodiversity Research, ${ }^{3}$ Institute of Geoscience \& Geography, Martin-Luther-University Halle-Wittenberg, Halle (Saale), Germany, ${ }^{4}$ UFZ Helmholtz Centre for Environmental Research, Department Community Ecology, ${ }^{5}$ Center for Systems Integration and Sustainability, Michigan State University, ${ }^{6}$ Yale School of Forestry and Environmental Studies, Yale University, ${ }^{7}$ UFZ - Helmholtz Centre for Environmental Research, Department of Community Ecology 
Table 1. Definition of the peak-rate year by category of resources.

\begin{tabular}{|c|c|c|}
\hline & Nonrenewable resources & Renewable resources \\
\hline Definition and property & $\begin{array}{l}\text { Finite amount, regenerates on geological time } \\
\text { scale }\end{array}$ & Regrowth each year, regenerates on human time scale \\
\hline Peak-rate year is the year... & $\begin{array}{l}\text {..of the maximum of the first derivative for the } \\
\text { smoothed time series of the cumulative } \\
\text { amount. }\end{array}$ & $\begin{array}{l}\text {..of the maximum of the first derivative for the } \\
\text { smoothed time series of the annual harvest. }\end{array}$ \\
\hline $\begin{array}{l}\text { The implication of a peak-rate year for } \\
\text { sustainable development is that... }\end{array}$ & $\begin{array}{l}\text {...societies are approaching limits of the } \\
\text { resource amount, if no change in technology, } \\
\text { etc. }\end{array}$ & $\begin{array}{l}\text {...societies are approaching limits of the ability to } \\
\text { increase regrowth, if no change in crop, etc. }\end{array}$ \\
\hline
\end{tabular}

with data on the consumption of animal products, the main sources of food are included in our analysis. We also evaluated resources with a long history of use, e.g., cropland and domesticated species, and renewable energy sources, which may be increasingly important in the future. Furthermore, we considered two global drivers of resource use, population and economic activity (world GDP). The database consists of time series of 27 global resources, 2 global drivers, and 13 national resources/drivers. The data sources are listed in Table 2. All data is accessible at Figshare http://dx.doi.org/10.6084/m9.figshare.929619. The raw data and smoothed times series of the bootstrap resamples (see Methods) are plotted in Figure 2.

\section{METHODS}

\section{Peak-rate year estimation}

We used a method that is standardized, nonparametric, generalizable, and allows analysis of nonrenewable and renewable resources. Renewable resources regenerate on shorter time scales, i.e., harvest rate and regrowth have comparable time scales, and have a human scale, and annual production is the response variable that was analyzed. Nonrenewables are regenerated on geological time scales, and the response variable is the accumulated amount extracted. This choice of response variables allowed the analysis of all resources with the same mathematical method (Table 1, Fig. 1). To estimate a peak-rate year, the maximum increase rate of the time series must be calculated. It is possible to use a parametric model, e.g., a logistic curve or its derivative. However, nonparametric curve fitting offers advantages regarding the bias and does not require parametric assumptions or that a functional model be postulated, e.g., stationarity of rate of resource appropriation. This means that the different resources and drivers need not follow the same increase process (Gasser et al. 1984). Further, by using a bootstrap resample to estimate the uncertainty of the peak rate year estimate, we avoided distributional assumption. However, no prediction outside the range of the data can be performed.

Time series analysis of peak-rate years and synchrony testing We do provide a summary of the statistical analysis of the time series. Appendix 1 provides detailed documentation of conducted steps. Figure A1.1 in the appendix provides a graphical overview.
The time series of the 27 global resources, 2 global drivers, and 13 national resources/drivers (with length $n=12-112$, see Table 2) were subjected to a cubic smoothing spline to find the peak rate of resource appropriation, based on the maximum of the first derivative. This nonparametric method has no distributional assumptions, but does not enable predictions. We performed 5000 bootstrap resamples, and the $50^{\text {th }}$ percentile $\left(2.5\right.$ and $\left.97.5^{\text {th }}\right)$ was taken as the peak-rate year (uncertainty), unless the $50^{\text {th }}$ percentile was equal to the last year in the time series, in which case we concluded the rate of resource appropriation was still increasing.

To test the hypothesis of synchrony, we selected statistically independent time series. We performed ARIMA modelling of the 27 global resource time series and tested the residuals with a BoxPierce test of white noise. Haugh's test of dependence on all pairs of resources was performed on cross-correlation coefficient of the white noise residuals (Haugh 1976). We selected 20 statistically independent time series of resource, of which 16 presented a peakrate year. A peak-rate year from the 5000 bootstrap resamples for each of the 16 resources was randomly selected, and the mode of the resulting smoothed distribution of 16 peak-rate years obtained. This process was repeated 5000 times, and we estimated the synchrony as the median of the 5000 modes. A nonparametric goodness of fit test was performed with a uniform distribution as a null hypothesis, i.e., no mode implies no synchrony, and a critical value obtained by Monte Carle simulation (5000). The statistical tests were performed at a Type I error rate of 0.05 .

\section{RESULTS}

We observed that for 21 of the 27 global resources and for the 2 global drivers of resource use, there was a peak-rate year. For the 21 resources that had a peak-rate year (Table 3), all but 1 (cropland expansion) lay between 1960 and 2010 (Fig. 3). Given the long human history, this is a very narrow time window. The available data suggest that peak-rate years for several nonrenewable resources, i.e., coal, gas, oil, and phosphorus, have not yet occurred. This implies a continued acceleration of extraction, which is in accordance with earlier analysis for oil (Hallock et al. 2014) and phosphorus (Cordell et al. 2009).

Individual countries have detectable impacts on the global nonrenewable resource extraction rate. For example, in 2011 the 
Table 2. List of time series and data sources. Internet resources accessed on 9/2013.

\begin{tabular}{|c|c|c|c|c|c|}
\hline $\begin{array}{l}\text { Resource/ } \\
\text { Driver }\end{array}$ & Length & $\begin{array}{l}\text { First } \\
\text { Year }\end{array}$ & $\begin{array}{l}\text { Last } \\
\text { Year }\end{array}$ & Source & Unit \\
\hline Coal & 32 & 1980 & 2011 & $\begin{array}{l}\text { U.S. Energy Information Administration (http://www.eia. } \\
\text { gov/cfapps/ipdbproject/IEDIndex3.cfm) }\end{array}$ & $\begin{array}{l}\text { 1E8 short tons of primary } \\
\text { coal }\end{array}$ \\
\hline Cropland & 31 & 1700 & 2000 & Costanza et al. 2007 & 1E6 hectares \\
\hline Gas & 32 & 1980 & 2011 & U.S. Energy Information Administration & $\begin{array}{l}1 \text { E12 cubic feet dry } \\
\text { natural gas }\end{array}$ \\
\hline Irrigated area & 49 & 1961 & 2009 & Brown 2012 & 1E6 hectares \\
\hline Oil & 42 & 1970 & 2011 & U.S. Energy Information Administration & $\begin{array}{l}\text { 1E6 barrels production of } \\
\text { crude oil }\end{array}$ \\
\hline Peat & 77 & 1935 & 2011 & U.S. Geological Survey (http://minerals.usgs.gov) & $\begin{array}{l}\text { 1E6 metric tons gross } \\
\text { weight }\end{array}$ \\
\hline Phosphate & 112 & 1900 & 2011 & U.S. Geological Survey & $\begin{array}{l}\text { 1E6 metric tons gross } \\
\text { weight of phosphate rock }\end{array}$ \\
\hline Cassava & 51 & 1961 & 2011 & FAO 2013 & $1 \mathrm{E} 6$ tons \\
\hline Cotton & 51 & 1961 & 2011 & FAO 2013 & 1E6 tons \\
\hline Dairy & 51 & 1961 & 2011 & FAO 2013 & $1 \mathrm{E} 6$ tons \\
\hline Eggs & 50 & 1961 & 2010 & FAO 2013 & 1E6 tons \\
\hline Fertilizer, $\mathrm{N}$ & 50 & 1961 & 2010 & $\begin{array}{l}\text { International Fertilizer Industry Association (http://www. } \\
\text { fertilizer.org/ifa/ifadata/search) }\end{array}$ & 1E6 tons \\
\hline Fish, caught & 61 & 1950 & 2010 & $\begin{array}{l}\text { Earth Policy Institute (http://www.earth-policy.org/ } \\
\text { data center/) }\end{array}$ & 1E6 tons \\
\hline Fish, farmed & 61 & 1950 & 2010 & Earth Policy Institute & $1 \mathrm{E} 6$ tons \\
\hline Maize & 51 & 1961 & 2011 & FAO 2013 & 1E6 tons \\
\hline Meat & 50 & 1961 & 2010 & FAO 2013 & 1E6 tons \\
\hline Meat, indigenous & 50 & 1961 & 2010 & FAO 2013 & 1E6 tons \\
\hline Meat, poultry & 50 & 1961 & 2010 & FAO 2013 & 1E6 tons \\
\hline Milk & 50 & 1961 & 2010 & FAO 2013 & 1E6 tons \\
\hline Oilpalm & 51 & 1961 & 2011 & FAO 2013 & $1 \mathrm{E} 6$ tons \\
\hline Renew. energy & 31 & 1980 & 2010 & U.S. Energy Information Administration & 1E9 Kilowatthours \\
\hline Rice & 51 & 1961 & 2011 & FAO 2013 & 1E6 tons \\
\hline Soybeans & 51 & 1961 & 2011 & FAO 2013 & 1E6 tons \\
\hline Sugarcane & 51 & 1961 & 2011 & FAO 2013 & 1E6 tons \\
\hline Vegetables & 51 & 1961 & 2011 & FAO 2013 & $1 \mathrm{E} 6$ tons \\
\hline Wheat & 51 & 1961 & 2011 & FAO 2013 & 1E6 tons \\
\hline Wood & 51 & 1961 & 2011 & Earth Policy Institute & $1 \mathrm{E} 6 \mathrm{cu}$. meters \\
\hline GDP & 52 & 1961 & 2012 & World Bank 2014 & 1E12 current US dollar \\
\hline Population & 52 & 1961 & 2012 & World Bank 2014 & individuals \\
\hline Hous. intensity Australia & 14 & 1911 & 2001 & Peterson et al. 2013 & $\begin{array}{l}\text { Number of households } \\
\text { per } 100 \text { people }\end{array}$ \\
\hline Hous. intensity Canada & 18 & 1881 & 2001 & Peterson et al. 2013 & $\begin{array}{l}\text { Number of households } \\
\text { per } 100 \text { people }\end{array}$ \\
\hline Hous. intensity China & 43 & 1955 & 1997 & Peterson et al. 2013 & $\begin{array}{l}\text { Number of households } \\
\text { per } 100 \text { people }\end{array}$ \\
\hline Hous. intensity England & 22 & 1600 & 2001 & Peterson et al. 2013 & $\begin{array}{l}\text { Number of households } \\
\text { per } 100 \text { people }\end{array}$ \\
\hline Hous. intensity Ireland & 36 & 1718 & 2002 & Peterson et al. 2013 & $\begin{array}{l}\text { Number of households } \\
\text { per } 100 \text { people }\end{array}$ \\
\hline Hous. intensity Japan & 23 & 1893 & 2000 & Peterson et al. 2013 & $\begin{array}{l}\text { Number of households } \\
\text { per } 100 \text { people }\end{array}$ \\
\hline $\begin{array}{l}\text { Hous. intensity } \\
\text { Luxembourg }\end{array}$ & 21 & 1864 & 2001 & Peterson et al. 2013 & $\begin{array}{l}\text { Number of households } \\
\text { per } 100 \text { people }\end{array}$ \\
\hline $\begin{array}{l}\text { Hous. intensity New } \\
\text { Zealand }\end{array}$ & 25 & 1874 & 2001 & Peterson et al. 2013 & $\begin{array}{l}\text { Number of households } \\
\text { per } 100 \text { people }\end{array}$ \\
\hline Hous. intensity USA & 17 & 1790 & 2000 & Peterson et al. 2013 & $\begin{array}{l}\text { Number of households } \\
\text { per } 100 \text { people }\end{array}$ \\
\hline Meat, USA & 104 & 1909 & 2012 & Earth Policy Institute & $1 \mathrm{E} 9 \mathrm{~kg}$ \\
\hline No. spp. dom. & 23 & 9000 & 1400 & $\begin{array}{l}\text { Hirst, K. K. (http://archaeology.about.com/od/ } \\
\text { domestications/a/plant domestic.htm) }\end{array}$ & Count \\
\hline Patent, USA & 61 & 1952 & 2012 & U.S. Patent and Trademark Office 2013 & $1 \mathrm{E} 3$ count \\
\hline Water, USA & 12 & 1950 & 2005 & Earth Policy Institute & $\begin{array}{l}\text { 1E9 liters groundwater } \\
\text { withdrawal }\end{array}$ \\
\hline
\end{tabular}


Fig. 2. For the global resources and drivers, the raw data is plotted as blue points. The nonrenewable resources are accumulated over time for growth rate analysis and for the renewable resources the yearly production is analyzed. The grey to black lines each represent one smoothed time series of the bootstrap resamples (5000). A wider set of lines implies larger uncertainty when estimating peak-rate year, e.g., compare peat vs. wheat. The uncertainty can be so small that the blue points hide the smoothed time series, e.g., population. There are local minima and maxima, which increase the uncertainty, e.g., wood.
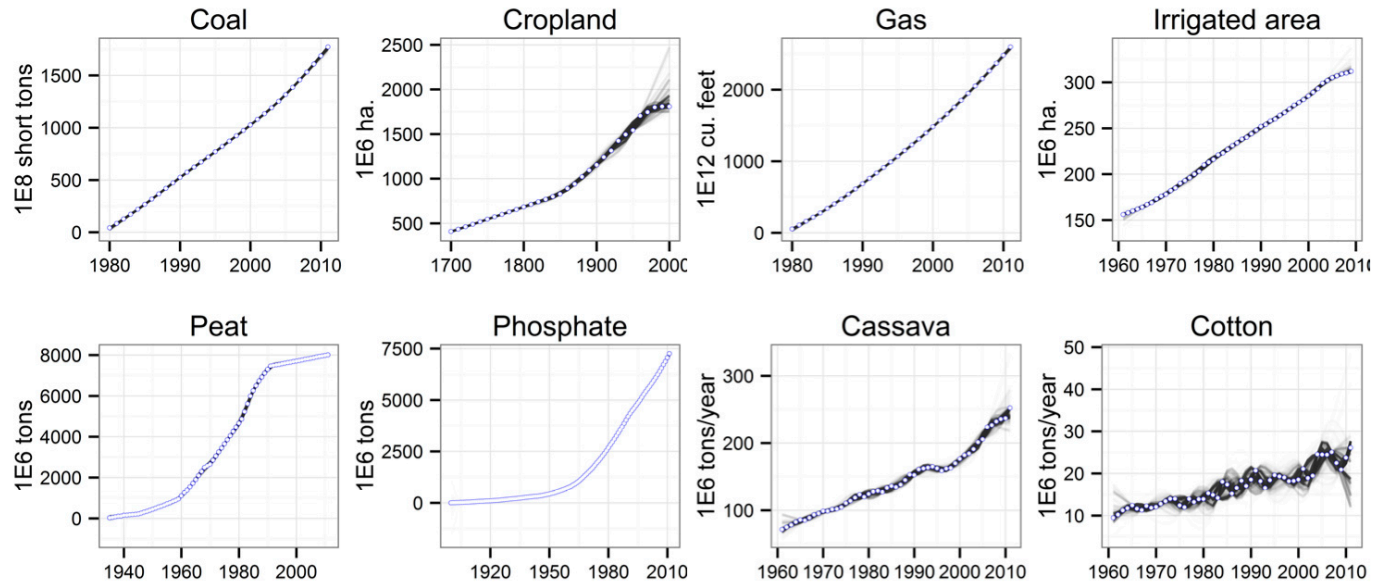

Fish, caught
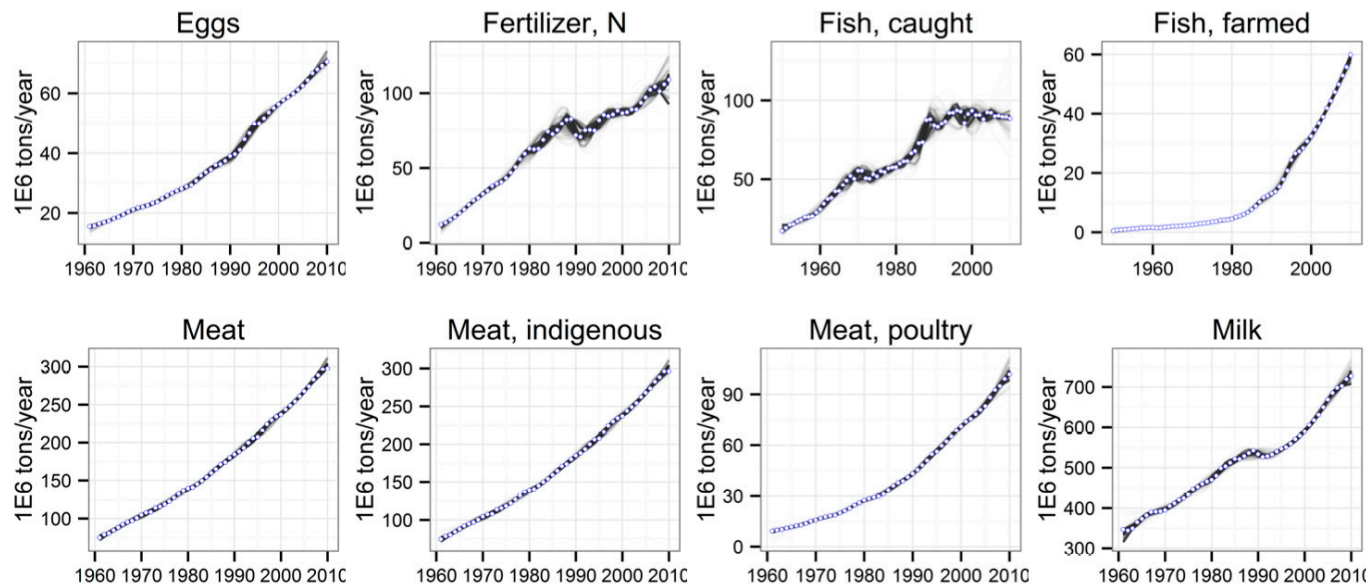

Rice
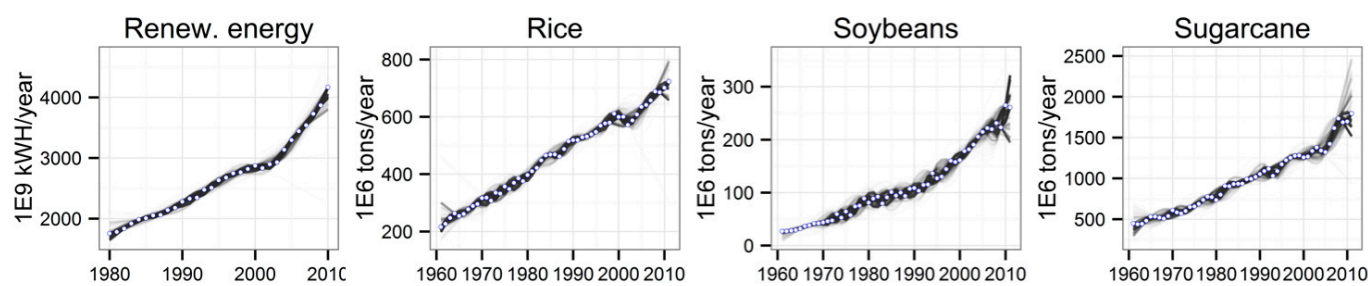

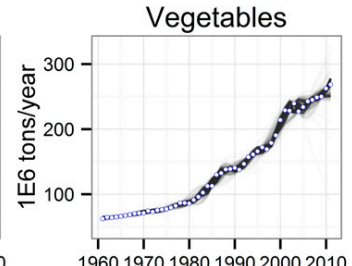

Oil

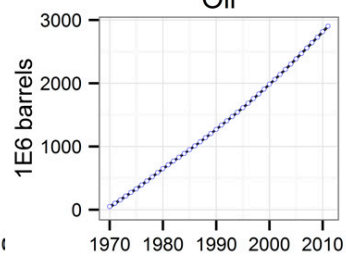

Dairy
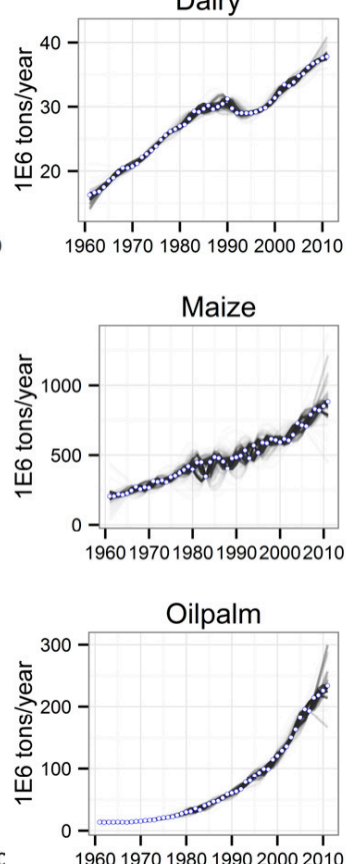

196019701980199020002010
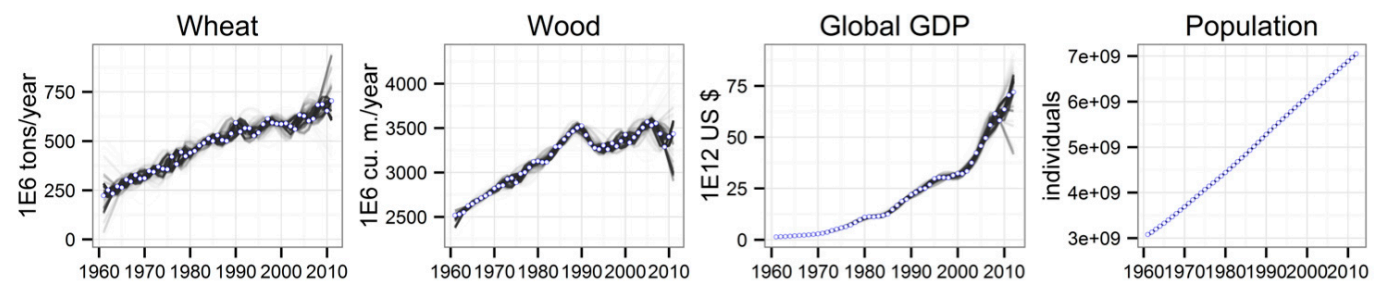
Table 3. Lists of results for all resources and drivers: peak-rate year (50th percentile from the bootstrap distribution of year of the maximum of the first derivative of the spline smoothed bootstrap time series resample) of extraction of nonrenewable resources, harvest of renewable resources, and growth of drivers. When the 50th percentile is equal to the last year in the time series, it is concluded that no peak-rate year was detected, suggesting a still accelerating rate. The standardized growth rate at the peak-rate year with uncertainty is also provided.

\begin{tabular}{|c|c|c|c|c|c|c|c|c|}
\hline & \multicolumn{4}{|c|}{ Peak-rate year } & \multicolumn{3}{|c|}{ Rate at peak } & \multirow[t]{2}{*}{ Independence } \\
\hline & $2.5^{\text {th }}$ & $50^{\text {th }}$ & $97.5^{\text {th }}$ & Peak? & $2.5^{\text {th }}$ & $50^{\text {th }}$ & $97.5^{\text {th }}$ & \\
\hline \multicolumn{9}{|l|}{ Global nonrenewable resources } \\
\hline Coal & 2008 & 2011 & 2011 & No peak & 4.2 & 4.7 & 4.9 & Yes \\
\hline Cropland & 1920 & 1950 & 1960 & Peak & 0.5 & 0.6 & 0.9 & Yes \\
\hline Gas & 2007 & 2011 & 2011 & No peak & 4.1 & 4.5 & 4.6 & Yes \\
\hline Irrigated area & 1976 & 1978 & 2003 & Peak & 1.5 & 1.8 & 2.3 & Yes \\
\hline Oil & 2006 & 2011 & 2011 & No peak & 2.9 & 3.1 & 3.1 & Yes \\
\hline Peat & 1982 & 1983 & 1983 & Peak & 4.1 & 5.0 & 5.2 & No \\
\hline Phosphate & 1988 & 2011 & 2011 & No peak & 2.3 & 2.8 & 3.1 & No \\
\hline \multicolumn{9}{|l|}{ Global renewable resources } \\
\hline Cassava $^{\dagger}$ & 2004 & 2006 & 2011 & Peak & 3.8 & 6.4 & 7.7 & Yes \\
\hline Cotton $^{\dagger}$ & 1983 & 2004 & 2011 & Peak & 9.6 & 14.8 & 19.2 & No \\
\hline Dairy & 1964 & 1989 & 2004 & Peak & 2.5 & 3.3 & 4.0 & No \\
\hline Eggs & 1992 & 1993 & 2006 & Peak & 3.2 & 4.4 & 5.5 & Yes \\
\hline Fertilizer, $\mathrm{N}^{\dagger}$ & 1978 & 1983 & 2010 & Peak & 4.7 & 6.2 & 7.0 & Yes \\
\hline Fish, caught & 1984 & 1988 & 1999 & Peak & 5.2 & 9.7 & 14.9 & Yes \\
\hline Fish, farmed & 1994 & 2010 & 2010 & No peak & 5.1 & 6.1 & 7.7 & No \\
\hline Maize & 1983 & 1985 & 2007 & Peak & 6.8 & 10.5 & 14.0 & Yes \\
\hline Meat & 1996 & 1996 & 2009 & Peak & 2.5 & 3.1 & 3.4 & Yes \\
\hline Meat, indigenous & 1996 & 1996 & 2009 & Peak & 2.6 & 3.1 & 3.3 & No \\
\hline Meat, poultry & 2005 & 2006 & 2009 & Peak & 3.6 & 4.8 & 5.5 & Yes \\
\hline Milk & 1982 & 2004 & 2009 & Peak & 2.4 & 2.7 & 2.8 & Yes \\
\hline Oilpalm & 2003 & 2005 & 2008 & Peak & 6.2 & 8.0 & 10.1 & Yes \\
\hline Renew. energy & 2004 & 2010 & 2010 & No peak & 3.8 & 5.7 & 8.3 & Yes \\
\hline Rice & 1973 & 1988 & 2008 & Peak & 3.6 & 4.4 & 5.0 & Yes \\
\hline Soybeans $^{\dagger}$ & 1977 & 2009 & 2011 & Peak & 5.9 & 8.9 & 21.4 & Yes \\
\hline Sugarcane $^{\dagger}$ & 1981 & 2007 & 2011 & Peak & 5.9 & 9.8 & 10.7 & Yes \\
\hline Vegetables & 1986 & 2000 & 2002 & Peak & 5.2 & 7.8 & 8.8 & No \\
\hline Wheat $^{\dagger}$ & 1975 & 2004 & 2011 & Peak & 6.9 & 9.5 & 11.8 & Yes \\
\hline Wood $^{\dagger}$ & 1976 & 2004 & 2011 & Peak & 2.2 & 3.1 & 5.1 & Yes \\
\hline \multicolumn{9}{|l|}{ Global drivers } \\
\hline $\mathrm{GDP}^{\dagger}$ & 2004 & 2010 & 2012 & Peak & 6.8 & 10.2 & 13.9 & NA \\
\hline Population & 1988 & 1989 & 1989 & Peak & 1.3 & 1.3 & 1.3 & NA \\
\hline \multicolumn{9}{|c|}{ National drivers and resources, biodiversity } \\
\hline Hous. intensity Australia & 1971 & 1976 & 1991 & Peak & 1.1 & 1.4 & 1.6 & NA \\
\hline Hous. intensity Canada & 1971 & 1976 & 1981 & Peak & 1.1 & 1.7 & 1.9 & NA \\
\hline Hous. intensity China & 1960 & 1960 & 1988 & Peak & 2.0 & 3.2 & 3.7 & NA \\
\hline Hous. intensity England $^{\dagger}$ & 1931 & 1981 & 2001 & Peak & 0.6 & 0.7 & 0.7 & NA \\
\hline Hous. intensity Ireland ${ }^{\dagger}$ & 1981 & 1996 & 2002 & Peak & 0.6 & 1.1 & 1.2 & NA \\
\hline Hous. intensity Japan & 1960 & 1965 & 1995 & Peak & 1.3 & 2.1 & 2.4 & NA \\
\hline Hous. intensity Luxembourg ${ }^{\dagger}$ & 1930 & 1970 & 2001 & Peak & 0.6 & 0.7 & 0.9 & NA \\
\hline Hous. intensity New Zealand & 1976 & 1976 & 1986 & Peak & 0.8 & 1.0 & 1.2 & NA \\
\hline Hous. intensity $\mathrm{USA}^{\dagger}$ & 1940 & 1970 & 2000 & Peak & 0.6 & 0.9 & 1.2 & NA \\
\hline Meat, USA & 1909 & 1955 & 1999 & Peak & 2.4 & 3.6 & 8.8 & NA \\
\hline No. spp. dom. & -3500 & -2600 & -1500 & Peak & 0.0 & 0.1 & 0.1 & NA \\
\hline Patents, $\mathrm{USA}^{\dagger}$ & 1997 & 2010 & 2012 & Peak & 9.5 & 14.8 & 24.8 & NA \\
\hline Water, $\mathrm{USA}^{\dagger}$ & 1975 & 1975 & 2005 & Peak & 2.0 & 2.1 & 2.1 & NA \\
\hline \multicolumn{9}{|c|}{$\begin{array}{l}{ }^{7} \text { Resources show a peak-rate year but the } 97.5^{\text {th }} \text { percentile year equals the last year of the time series indicating that the upper uncertainty inter } \\
\text { is truncated. } \\
{ }^{\ddagger} \text { Time series of drivers and of national resources are not tested for independence (NA: Not Applicable) because they are not used to test } \\
\text { synchrony, which is based only on global resources. These global resources have to be statistically independent so that peat, phosphate, cotton, } \\
\text { dairy, fish farmed, indigenous meat, and vegetables are removed to leave a set of statistically independent global resources. See Tables A1.1 and } \\
\text { A1.2 for details }\end{array}$} \\
\hline$\cdot$ & & & & & & & & \\
\hline
\end{tabular}


Fig. 3. Estimated peak-rate year (median) of global resources and drivers ( 21 out of 27 resources, and 2 out of 2 drivers). The uncertainty bars represent 2.5 th and 97.5 th percentiles of 5000 bootstrap estimates. Point size denotes the relative growth rate in $\%$ in the year of maximum growth. The bootstrap distribution of peak-rate year is skewed with the peak-rate year often not centered in the confidence interval.

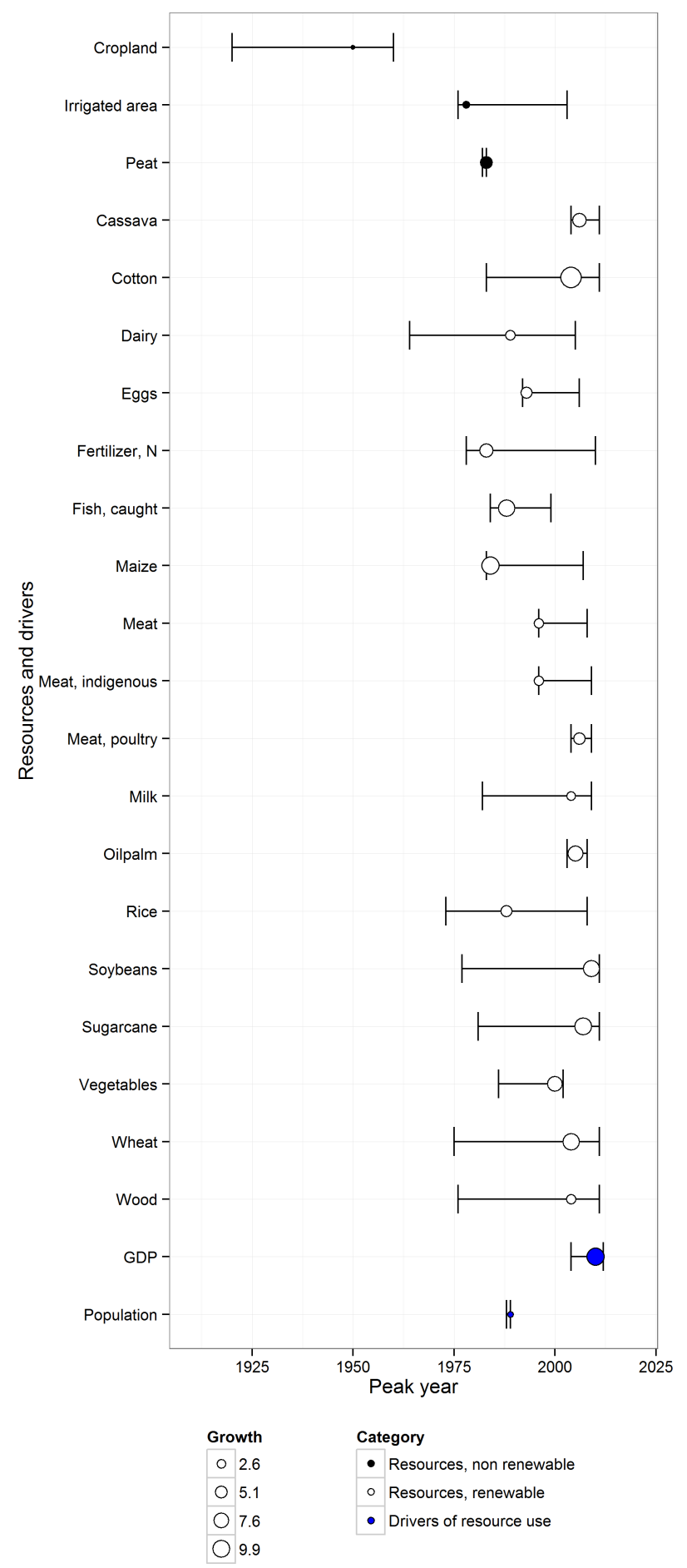

Erratum: In the original publication of Figure 3 the data for milk and wood were erroneous. A correction was made on 24 February 2015. rate of coal extraction for China was 7.2\% (5.7-7.4), whereas the rate for the world without China was $3.7 \%$ (3.5-3.8). The values for natural gas in 2011 were $10.1 \%$ (7.6-10.3) and 4.4\% (4.0-4.4) with and without China, respectively. A peak-rate year for renewable energy has not occurred.

Figure 3 shows that the peak rate of earth surface conversion to cropland occurred in 1950 (1920-1960), and the expansion of cropland recently stabilized at the highest recorded levels, about $1.8 \times 10^{6}$ ha (Ramankutty and Foley 1999). We find peak-rate years recently passed for many agricultural products: soybeans in 2009 (1977-2011), milk in 2004 (1982-2009), eggs in 1993 (1992-2006), caught fish in 1988 (1984-1999), and maize in 1985 (1983-2007). Two major factors of agricultural productivity, Nfertilizers and the area of irrigated land, show peak-rate years in 1983 (1978-2010) and 1978 (1976-2003), respectively. Water is a resource that many world policy bodies are concerned with and is largely understood as a renewable resource. But not all water is renewable. 'Fossil water' stocks are isolated water resources, which are consumed faster than are naturally renewed. There is currently a lack of time-series data at the global scale on the status of hydrological resources (Fan et al.2013). As an example of national trends, the greatest rate of groundwater extraction occurred in 1975 in the USA (1975-2005). Water conservation and rationing rules likely reduced the rate of ground water extraction (Gleick and Palaniappan 2010). For maize, rice, wheat, and soybeans, the yield per area is stagnating or collapsing in $24-39 \%$ of the world's growing areas (Ray et al. 2012), which may explain why the peakrate years have passed at a global level. The peak-rate years of renewable resources collectively suggest challenges to achieving global food security (Foley et al. 2011). We identified a sequence in the peak-rate years of resources associated with food production: 1950 for conversion to cropland, 1978 for conversion to irrigated land, 1983 for fertilizer use. Because all peak-rate years for food resources appeared afterward, we inferred that the strategies to increase food production changed from land expansion to intensification of production. Furthermore, the pattern of peak-rate years occurring in land, food, and not yet for nonrenewable resources suggests that sustained intensification of agricultural production is not limited by energy but rather by land.

Following the observation of an apparently simultaneous pattern of peak-rate years in Figure 3, we tested the hypothesis of synchrony among peak-rate years on 20 statistically independent time series of resources, of which 16 presented a peak-rate year. We found that peak-rate years appeared clustered around 2006 (1989-2008), given the uncertainty surrounding the peak-rate year estimate of each resource (Fig. 4). It is unlikely that the synchrony is a statistical artefact because there is less than a 1 in 1000 chance that the distribution in Figure 4 would have been obtained if it were sampled from a uniform distribution, i.e., null hypothesis of no synchrony is rejected.

\section{DISCUSSION}

Why is there a synchrony of peak-rate years? Some explanations follow. The overall hypothesis is that multiple resources become scarce simultaneously, which can be driven by two mechanisms. 
Fig. 4. Synchrony of the peak-rate years is evident. For each of the 16 out of 20 statistically independent global resources showing a peak-rate year, one peak-rate year out of the 5000 from the bootstrap resample was randomly selected. The mode of the resulting smoothed distribution of 16 peak-rate years was obtained, and the process repeated 5000 times resulting in the mode histogram, with a median of 2006 (1989-2008) in red. A nonparametric goodness of fit test rejected $(\mathrm{P}<0.001)$ the two-sided null hypothesis that the histogram was sampled from a uniform distribution (i.e., no synchrony).

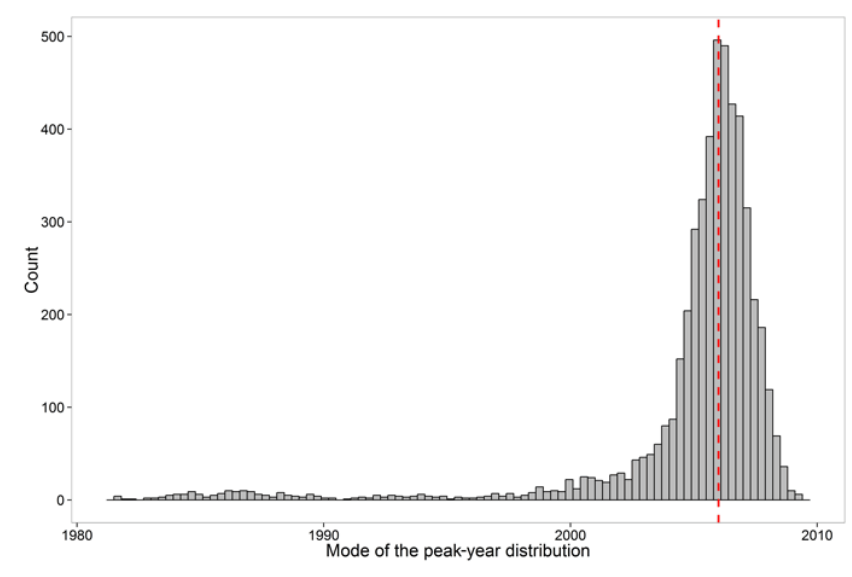

First, multiple resources, e.g., land, food, energy, etc., are consumed at the same time to meet different human needs. For example, people require food for nutrition; water for drinking, irrigation, and cleaning; land for housing, recreation, food production, infrastructure; and energy for cooking food, transportation, heating, cooling, etc.

Second, producing one resource requires the use of other resources. For example increasing food production requires more land and water whose scarcity in turn leads to limited food production increases, as the sequence of peak-rate years associated with food production shows (see above). Furthermore, the continued increase in extraction for less accessible resources results in an increased ecological and economic cost per unit extracted (Davidson and Andrews 2013), thus reducing availability of the remaining resources. For example, pollution exacerbates water shortages because polluted water is not suitable. These two mechanisms provide the most parsimonious explanation for simultaneous scarcity leading to synchrony of peak-rate years.

Are there other factors causing synchronized peak-rate years? Besides scarcity, passing an individual peak-rate year may be caused by two possible reasons: availability of substitutes or less demand, e.g. less resource is needed because of more efficient use, taste changes, or institutional and regulatory changes (Fig. 1). It is unlikely that substitution has a substantial influence on synchronization. Strong support for the hypothesis that substitution synchronized the peaks would require that substitution took place for all or most of the resources with synchronized peak-rate years. However, among the 16 resources with synchronized peak-rate years in our database, which contains most of the critical global resources, only a few resources may have substitutes. For instance, contrary to expectation there is little evidence that farmed fish substitutes for caught fish (Asche et al. 2001). In contrast, poultry products serve as a substitute for beef because they are cheaper and better adapted to changing tastes (Eales and Unnevehr 1988). However, evidence suggests that meat as a category is not being substituted by plant protein on a global scale (Daniel et al. 2011). Finally, there is little evidence that renewable energy, which did not show a peak-rate year, substitutes for fossil energy. In the last 50 years, the general global trend was that a unit of energy sourced from nonfossil fuels substituted less than one quarter of a unit of fossil fuel-based energy, possibly as a consequence of economic and social complexity (York 2012).

A global synchronous reduction of demand is also an unlikely driver. Despite a declining global population growth rate, i.e., peak-rate year passed in 1989 in accordance with preceding reports (Lutz and K. C. 2010), the global population continues to grow. In most developed countries, we identified peak-rate years in household intensity, i.e., number of households per 100 people (Table 2). Additionally, the peak rate of meat consumption in the USA occurred in 1955 (1909-1999). Nevertheless, the rate of resource appropriation is not expected to decline because consumption in developing countries increases because of lifestyle changes (Brown 2012, Liu 2014), and the land area used for urban settlements and household numbers continue to increase (Liu et al. 2003, Seto et al. 2011). These shifts in resourceintensive living likely more than offset the declining rate of population growth. Declining demand would have to come from broad scale changes in individual preferences for conservation, which continue to seem unlikely.

Finally, constraints on production may not be alleviated unless there is disruptive innovation. For example, although there is phenotypic plasticity in plants, which is exploited by agronomic research, e.g. breeding, particular biochemical mechanisms were not as of now disrupted or constructed de novo in a commercial setting: nitrogen fixation for cereals remains elusive (Charpentier and Oldroyd 2010) and further increase in photosynthetic efficiency is expected to be hard to achieve (Zhu et al. 2010). Further, a basic constraint on breeding is biological diversity. The rate of domesticating species, the biological foundation of food provisioning, began to slow around 2600 B.C. (3600-1500 B.C.), well before our era.

Synchrony among the peak-rate years suggests that multiple planetary resources have to be managed simultaneously, accounting for resource distribution and utilization (Steffen et al. 2011, Liu et al. 2013). Synchrony does not necessarily imply a tipping point that leads to disastrous outcomes because trade-offs are possible (Seppelt et al. 2013), and adaptation, such as the current increasing rate of renewable energy generation or shifting diets (Foley et al. 2011), potentially can be accelerated. Synchrony also suggests that the debate about whether humans can devise substitutes for individual natural capital needs to be broadened to assess simultaneous substitutability (Barbier et al. 2011). Whether substitution and recycling will alleviate constraints to future economic growth (Neumayer 2002) remains an open question, especially because maintaining the innovation rate requires increasing expenditures on human capital (Huebner 
2005, Fenichel and Zhao 2014). Arrow et al. (2012) estimated that the growth rate of human capital in the United States could be as low as $0.35 \%$, which is $15-44 \%$ of the growth rate of conventional reproducible capital, e.g., infrastructure, and China's rate of human capital growth ranges between $1.1 \%$ and $2 \%$, but is only $10-17 \%$ of the rate of growth in reproducible capital.

The synchronization of peak-rate years of global resource appropriation can be far more disruptive than a peak-rate year for one resource. Peak-rate year synchrony suggests that the relationship among resource appropriation paths needs to be considered when assessing the likelihood of successful adaptation of the global society to physical scarcity.

Responses to this article can be read online at: http://www.ecologyandsociety.org/issues/responses. $\mathrm{php} / 7039$

\section{Acknowledgments:}

We are grateful to Anna Cord, Jörg Priess, Nina Schwarz, Dagmar Haase, and Burak Guneralp for providing comments on earlier versions of the manuscript. We also thank Karen Seto and Burak Gunneralp for providing access to the urban growth data. The work was funded by grant 01 LL0901 A "Global Assessment of Land Use Dynamics, Greenhouse Gas Emissions and Ecosystem Services GLUES" (German Ministry of Research and Technology) under the Helmholtz Program "Terrestrial Environmental Research," $U$. S. National Science Foundation, and Michigan AgBioResearch. This article contributed to the Global Land Project (www. globallandproject.org).

\section{LITERATURE CITED}

Arrow, K. J., B. Bolin, R. Costanza, P. Dasgupta, C. Folke, C. S. Holling, B.-O. Jansson, S. Levin, K.-G. Mäler, C. Perrings, and D. Pimentel. 1995. Economic growth, carrying capacity, and the environment. Science 268:520-521. http://dx.doi.org/10.1126/ science. 268.5210 .520

Arrow, K. J., P. Dasgupta, L. H. Goulder, K. J. Mumford, and K. Oleson. 2012. Sustainability and the measurement of wealth. Environment and Development Economics 17:317-353. http://dx. doi.org/10.1017/S1355770X12000137

Asche, F., T. Bjørndal, and J. A. Young. 2001. Market interactions for aquaculture products. Aquaculture Economics and Management 5(5-6):303-318. http://dx.doi.org/10.1080/1365730$\underline{0109380296}$

Barbier, E. B. 2011. Capitalizing on nature: ecosystems as natural assets. Cambridge University Press, New York, New York, USA. http://dx.doi.org/10.1017/CBO9781139014922

Bardi, U. 2000. The limits to growth revisited. Springer, New York, New York, USA. http://dx.doi.org/10.1007/978-1-4419-9416-5

Brown, L. R. 2012. Full planet, empty plates: the new geopolitics of food scarcity. Earth Policy Institute, Washington, D.C., USA. [online] URL: http://www.earth-policy.org/books/fpep
Charpentier, M., and G. Oldroyd. 2010. How close are we to nitrogen-fixing cereals? Current Opinion in Plant Biology 13:556-564. http://dx.doi.org/10.1016/j.pbi.2010.08.003

Cordell, D., J.-O. Drangert, and S. White. 2009. The story of phosphorus: global food security and food for thought. Global Environ Change 19:292-305. http://dx.doi.org/10.1016/j. gloenvcha.2008.10.009

Costanza, R., L. Graumlich, W. Steffen, C. Crumley, J. Dearing, K. Hibbard, R. Leemans, C. Redman, and D. Schimel. 2007. Sustainability or collapse: what can we learn from integrating the history of humans and the rest of nature? Ambio 36:522-527. http://dx.doi.org/10.1579/0044-7447(2007)36[522:SOCWCW]2.0. $\mathrm{CO} ; 2$

Daniel, C. R., A. J. Cross, C. Koebnick, and R. Sinha. 2011. Trends in meat consumption in the United States. Public Health Nutrition 14(4):575-583. http://dx.doi.org/10.1017/S1368980010002077

Davidson, D. J., and J. Andrews. 2013. Not all about consumption. Science 339:1286-1287. http://dx.doi.org/10.1126/science.1234205

Eales, J. S., and L. J. Unnevehr. 1988. Demand for beef and chicken product: separability and structural change. American Journal of Agricultural Economics 70:521-532. http://dx.doi. org/10.2307/1241490

Fan, Y., H. Li, and G. Miguez-Macho. 2013. Global patterns of groundwater table depth. Science 339:940-943. http://dx.doi. org/10.1126/science.1229881

Fenichel, E. P., and J. Zhao. 2014. Sustainability and substitutability. Bulletin of Mathematical Biology May 2014. http://dx.doi.org/10.1007/s11538-014-9963-5

Foley, J. A., N. Ramankutty, K. A. Brauman, E. S. Cassidy, J. S. Gerber, M. Johnston, N. D. Mueller, C. O'Connell, D. K. Ray, P. C. West, C. Balzer, E. M. Bennett, S. R. Carpenter, J. Hill, C. Monfreda, S. Polasky, J. Rockström, J. Sheehan, S. Siebert, D. Tilman, and D. P. M. Zaks. 2011. Solutions for a cultivated planet. Nature 478:337-342. http://dx.doi.org/10.1038/nature10452

Food and Agriculture Organization of the United Nations (FAO). 2013. FAOSTAT. Food and Agriculture Organization of the United Nations, Statistics Division. [online] URL: http://faostat3. fao.org/faostat-gateway/go/to/download/C/CC/E

Gasser, T., H.-G. Müller, W. Köhler, L. Molinari, and A. Prader. 1984. Nonparametric regression analysis of growth curves. Annals of Statistics 12:210-229. http://dx.doi.org/10.1214/ aos/1176346402

Gleick, P. H., and M. Palaniappan. 2010. Peak water limits to freshwater withdrawal and use. Proceedings of the National Acadamy of Science 107:11155-11162. http://dx.doi.org/10.1073/ pnas. 1004812107

Griggs, D., M. Stafford-Smith, O. Gaffney, J. Rockström, M. C. Öhman, P. Shyamsundar, W. Steffen, G. Glaser, N. Kanie, and I. Noble. 2013. Sustainable development goals for people and planet. Nature 495:305-307. http://dx.doi.org/10.1038/495305a

Hallock, Jr., J. L., W. Wu, C. A. S. Hall, and M. Jefferson. 2014. Forecasting the limits to the availability and diversity of global conventional oil supply: validation. Energy $64: 130-153$. http://dx. doi.org/10.1016/j.energy.2013.10.075 
Haugh, L. D. 1976. Checking the independence of two covariance stationary time series: a univariate residual cross-correlation approach. Journal of the American Statistical Association 71 (354):378-384. http://dx.doi.org/10.2307/2285318

Huebner, J. 2005. A possible declining trend for worldwide innovation. Technological Forecasting and Social Change 72:980-986. http://dx.doi.org/10.1016/j.techfore.2005.01.003

Liu, J. 2014. Forest sustainability in China and implications for a telecoupled world. Asia and the Pacific Policy Studies 1:230-250. http://dx.doi.org/10.1002/app5.17

Liu, J., G. C. Daily, P. R. Ehrlich, and G. W. Luck. 2003. Effects of household dynamics on resource consumption and biodiversity. Nature 421:530-533. http://dx.doi.org/10.1038/ $\underline{\text { nature } 01359}$

Liu, J., V. Hull, M. Batistella, R. DeFries, T. Dietz, F. Fu, T. W. Hertel, R. C. Izaurralde, E. F. Lambin, S. Li, L. A. Martinelli, W. J. McConnell, E. F. Moran, R. Naylor, Z. Ouyang, K. R. Polenske, A. Reenberg, G. de Miranda Rocha, C. S. Simmons, P. H. Verburg, P. M. Vitousek, F. Zhang, and C. Zhu. 2013. Framing sustainability in a telecoupled World. Ecology and Society 18(2): 26. http://dx.doi.org/10.5751/ES-05873-180226

Lutz, W., and S. K. C. 2010. Dimensions of global population projections: what do we know about future population trends and structures? Philosophical Transactions of the Royal Society B: Biological Sciences 365:2779-9. http://dx.doi.org/10.1098/ rstb.2010.0133

Malthus, T. R. 1798. An essay on the principle of population as it affects the future improvement of society. Printed for J. Johnson, in St. Paul's Church-Yard, London, UK.

Neumayer, E. 2002. Scarce or abundant? The economics of natural resource availability. Journal of Economic Surveys 14:307-335. http://dx.doi.org/10.1111/1467-6419.00112

Peterson, N., T. Peterson, and J. Liu. 2013. The housing bomb. Johns Hopkins University Press, Baltimore, Maryland, USA.

Ramankutty, N., and J. A. Foley. 1999. Estimating historical changes in global land cover: croplands from 1700 to 1992. Global Biogeochemical Cycles 13:997-1027. http://dx.doi. org/10.1029/1999GB900046

Ray, D. K., N. Ramankutty, N. D. Mueller, P. C. West, and J. A. Foley. 2012. Recent patterns of crop yield growth and stagnation. Nature communications 3:1293. http://dx.doi.org/10.1038/ $\underline{\text { ncomms } 2296}$

Seppelt, R., S. Lautenbach, and M. Volk. 2013. Identifying tradeoffs between ecosystem services, land use, and biodiversity: a plea for combining scenario analysis and optimization on different spatial scales. Current Opinion in Environmental Sustainability 5:458-463. http://dx.doi.org/10.1016/j.cosust.2013.05.002

Seto, K. C., M. Fragkias, B. Güneralp, and M. K. Reilly. 2011. A meta-analysis of global urban land expansion. PloS one 6:e23777. http://dx.doi.org/10.1371/journal.pone.0023777

Steffen, W., Å. Persson, L. Deutsch, J. Zalasiewicz, M. Williams, K. Richardson, C. Crumley, P. Crutzen, C. Folke, L. Gordon, M. Molina, V. Ramanathan, J. Rockström, M. Scheffer, H. J.
Schellnhuber, and U. Svedin. 2011. The Anthropocene: from global change to planetary stewardship. Ambio 40(7):739-761. http://dx.doi.org/10.1007/s13280-011-0185-x

Tollefson, J., and R. Monastersky. 2012. The global energy challenge: awash with carbon. Nature 491:654-655. http://dx.doi. org/10.1038/491654a

U.S. Patent and Trademark Office. 2013. U.S. Patent Statistics Chart Calendar Years 1963 - 2013. U.S. Patent and Trademark Office, Washington, D.C., USA. [online] URL: http://www.uspto. gov/web/offices/ac/ido/oeip/taf/us stat.htm

World Bank. 2014. Indicators. World Bank, Washington, D.C., USA. [online] URL: http://data.worldbank.org/indicator

York, R. 2012. Do alternative energy sources displace fossil fuels? Nature Climate Change 2:441-443. http://dx.doi.org/10.1038/ nclimate1451

Zhu, X.-G., S. P. Long, and D. R. Ort. 2010. Improving photosynthetic efficiency for greater yield. Annual Review of Plant Biology 61:235-261. http://dx.doi.org/10.1146/annurevarplant-042809-112206 


\section{Appendix 1: Time series analysis of peak-rate years and synchrony testing.}

\section{Overview}

The raw data are accessible at Figshare ("Time series of global resources", DOI 10.6084/m9.figshare.929619), sources are listed in Table 2.

A flowchart of the data analysis is in Figure S1.

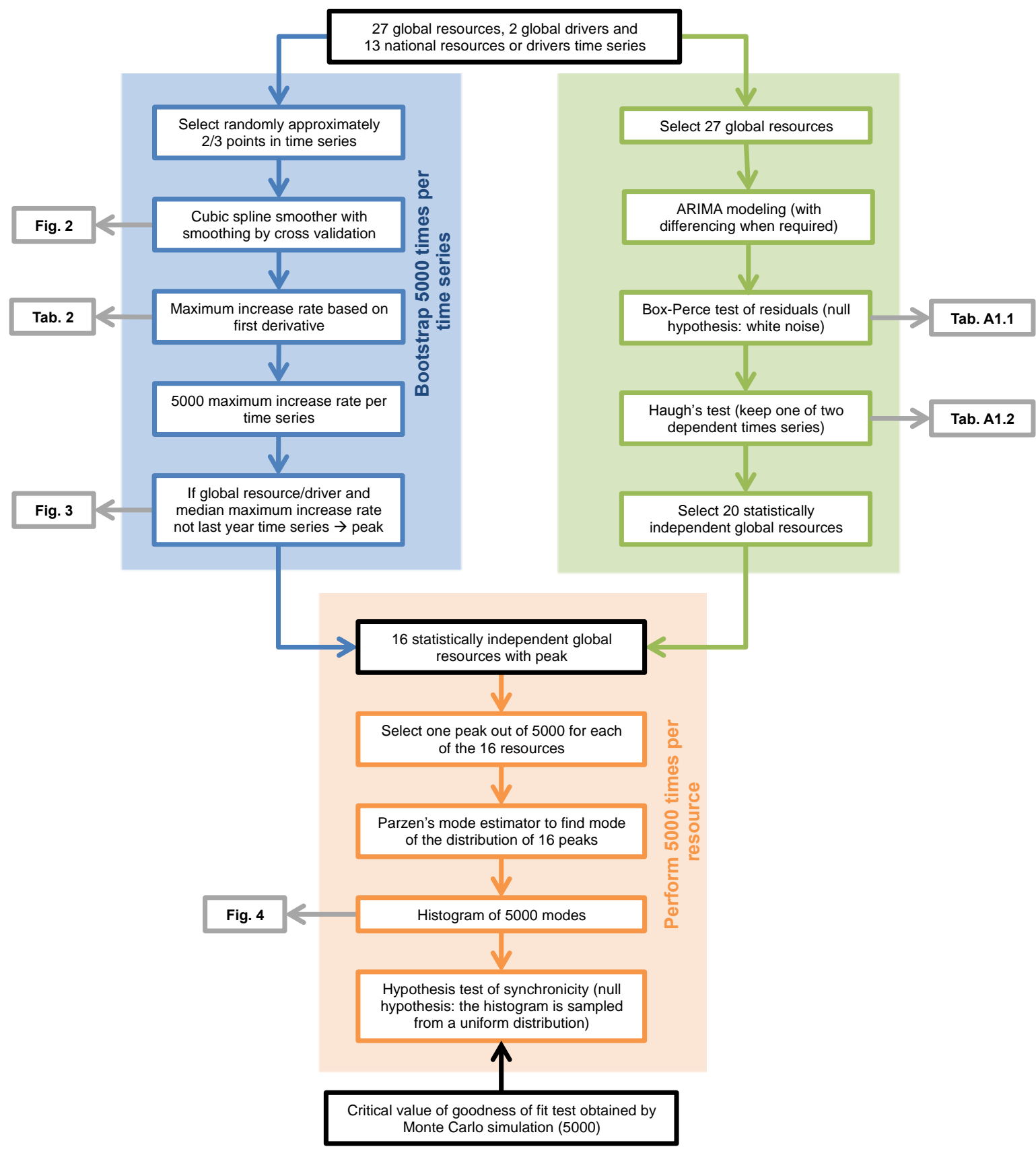

Figure A1.1: Flowchart of data analysis. Blue: peak-rate year detection and estimate. Green: time series analysis and statistically independent resource selection. Orange: test of the synchrony hypothesis. Gray: Output included in the paper. 


\section{Peak-rate year estimation}

We use a method that is standardized, nonparametric, generalizable, and allows analysis of nonrenewable and renewable resources. To estimate a peak-rate year, the maximum increase rate of the time series must be calculated. Nonparametric curve fitting offers advantages regarding the bias, and does not require parametric assumptions or that a functional model be postulated (e.g. stationarity of rate of resource appropriation). This means that the different resources and drivers need not follow the same increase process (Gasser 1984). By using a bootstrap resample to estimate the uncertainty of the peak-rate year estimate, we avoid distributional assumption. First, we divided each time series by its maximum value to scale the values between 0 and 1 . This does not affect the estimate of the year when the maximum rate of appropriation occurs, but it allows the estimation of the relative growth rate making the different time series comparable. Then, 5,000 bootstrap samples were obtained, leaving approximately $30-50 \%$ of the data out per sample. For each bootstrap sample, we fitted a cubic smoothing spline with a smoothing coefficient selected by generalized cross-validation. This resulted in limited smoothing, so the estimate of peak-rate year is minimally biased (but with greater variance). The peak-rate year is the year of the maximum of the first derivative of the cubic spline smoother. The $50^{\text {th }}$ percentile $\left(2.5-97.5^{\text {th }}\right)$ of the 5,000 bootstrap resamples was taken to be the peak-rate year with the uncertainty. The number of bootstrap resamples was sufficient to ensure that stable estimates were obtained. When the estimated peak-rate year was equal to the last year in the time series, we concluded that the peakrate year had not passed. This was performed in the software $R$ (R Core Team 2013).

\section{Test for independence among resources and drivers}

To test the hypothesis of synchrony (i.e. peak-rate years occur at the same time), we selected statistically independent time series to ensure the validity of the statistical test. To test the independence between two time series (on 27 resources), the trend and temporal autocorrelation must be taken into account. We subjected the time series (with $n>11$ ) to an automated ARIMA, autoregressive integrated moving average, $(p, d, q)$ modelling in $R$ where $p$ is the order of the autocorrelation component, $d$ the order of the differencing of the time series, and $q$ the order of the moving average component. The numbers of parameters of the model were selected using a parsimony measure (i.e. Akaike's "an information criterion" corrected for small sample size). Most time series required differencing to ensure stationarity at the first order (e.g. no trend in the mean) while a simple AR or MA adequately modelled the autocorrelation. We tested the residuals of the ARIMA modelled time series for their independence over time (i.e. white noise test) with a Box-Pierce test with degrees of freedom equal to $p+d+q$ and with number of lags equal to $10 * \log (n / 2)$, see table in Table A1.1.

We subjected the white noise residuals to Haugh's Chi-square test of independence between two time series (Haugh 1976). This test was performed on the cross-correlation coefficients of the white noise residuals with number of lags equal to $10 * \log (n / 2)$. When the two-sided null hypothesis of independence was rejected, one of the two time series was removed from the dataset, see Table A1.2. Note that a simple correlation analysis between two time series is an incorrect measure of linear association because of the autocorrelation. 
Table A1.1. $P$ values of the Box-Pierce test for global resources. This table shows that the time series can be used to perform Haugh's test of independence between two time series, which assumes that the residuals of the modelled time series do not present any temporal autocorrelation or trend (i.e. are white noise). Failing to reject $(P>0.05)$ the two-sided null hypothesis that the time series residuals are white noise implies that the time series can be used to perform Haugh's test.

\begin{tabular}{ll}
\hline Resource & $P$ value Box-Pierce test \\
\hline Coal & 0.228 \\
Cropland & 0.886 \\
Gas & 0.815 \\
Irrigated area & 0.667 \\
Oil & 0.757 \\
Peat & 0.141 \\
Phosphate & 0.498 \\
Cassava & 0.936 \\
Cotton & 0.086 \\
Dairy & 0.727 \\
Eggs & 0.980 \\
Fertilizer, N & 0.862 \\
Fish, caught & 0.805 \\
Fish, farmed & 0.403 \\
Maize & 0.902 \\
Meat & 0.799 \\
Meat, indigenous & 0.670 \\
Meat, poultry & 0.500 \\
Milk & 0.892 \\
Oilpalm & 0.801 \\
Renew. energy & 0.667 \\
Rice & 0.872 \\
Soybeans & 0.806 \\
Sugarcane & 0.842 \\
Vegetables & 0.577 \\
Wheat & 0.480 \\
Wood & 0.761 \\
\hline
\end{tabular}

\section{Estimation of the synchrony and test of hypothesis}

Out of the independent time series of resources, 16 presented a peak-rate year (Table 2 and A1.2). An inspection of the bootstrap distribution obtained for each suggested that for several resources the uncertainty about the median was not symmetric thus we developed a nonparametric test of the synchrony hypothesis. The question was whether the peak-rate year occurred at approximately the same time given the uncertainty in the estimate of the peak-rate year for each resource. For each of 16 resources where a peak-rate year was detected, a peak-rate year out of the 5,000 available was randomly selected (thus the full range of possible peak-rate year was sampled). The mode (most frequent value) of the resulting distribution of 16 peak-rate years was obtained using Parzen's kernel mode estimator with a Gaussian kernel density estimator whose bandwidth was chosen to minimize bias. The process was performed 5,000 times (i.e. 5,000 simulations) resulting in a distribution of 5,000 modes. If there is no detectable synchrony, then the distribution of 5,000 modes should be approximately uniform. To supplement a visual inspection of the histogram of modes, a nonparametric goodness of fit test was performed with a uniform distribution (e.g. no mode) as a null hypothesis using the package 'dbEmpLikGOF' (Miecznikowski et al. 2013) in $R$ after scaling the distribution of modes to match the support of the uniform distribution (0-1). The critical value of the test was obtained by Monte Carlo simulation $(5,000)$ and there is no need to rely on normality since the test is nonparametric. Rejecting the two-sided null hypothesis suggests synchrony: given the uncertainty in the peak-rate year estimate of each resource there is still a value which occurs most often on average (the year of synchrony of peak-rate years).

All statistical tests were performed at a Type I error rate of 0.05 . 
Table A1.2. $P$ values of Haugh test of independence between pairs of time series. This table allows the selection of time series which are statistically independent. Looking vertically and horizontally, pairs of time series which are significantly dependent are in red. By keeping only one of the two time series in the pair which is significantly dependent, a set of independent resources is selected. Specifically, failing to reject $(P>0.05)$ the two-sided null hypothesis of independence between time series imply that both resources can be used in peak-rate analyses. Highlighted numbers represent statistically significant dependence between the two time series at a Type I error rate of 0.05 , so that one of the two time series is excluded. As a result, peat, phosphate, fish farmed, indigenous meat, dairy, vegetables and cotton are not included in the hypothesis test of synchrony. The remaining time series represent a set of statistically independent resources

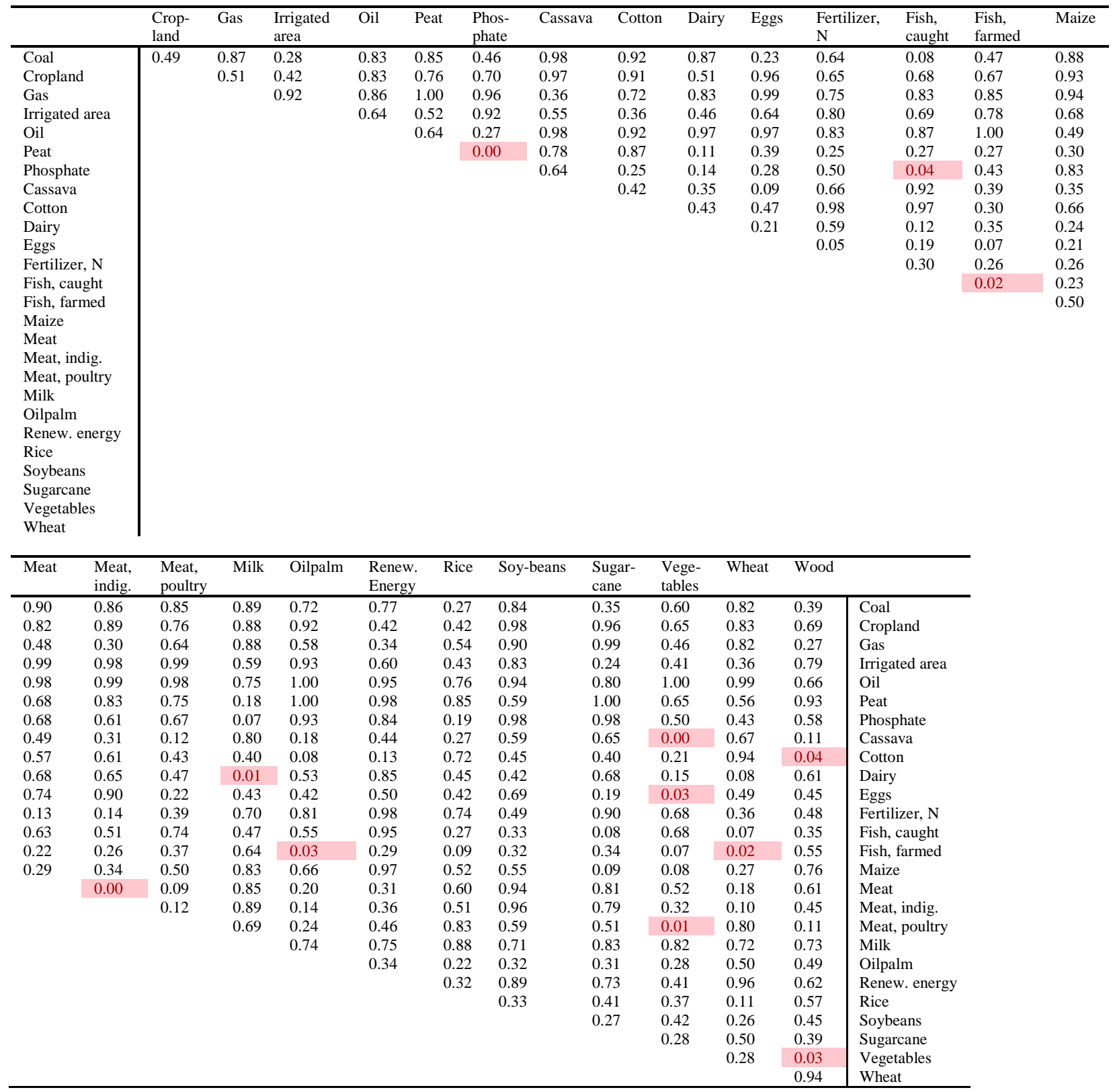




\section{Sources of uncertainty}

First, uncertainty of the identified peak-rate years is due to the limited length of the time series. A shorter time series increases the variance of the estimators as the sample size is reduced. In the bootstrap resample approach taken here a random sample, smaller than the original data series, is drawn which increases further the uncertainty surrounding the peak-rate year. Time series with several minima and maxima will result in large uncertainty of the peak-rate year estimate, an adequate representation of the noise in the time series. Second, technological and demand shifts make the time series nonstationary. Hence, we do not make model-based predictions (which would assume stationarity for statistical modelling) of rate of resource use, but detect peak-rate years in-sample for independent resources over a period where the demand for resources is not expected to decrease. New data in the future may shift the peak-rate year. Third, there is equifinality in the interpretation of a peak-rate year. For example, a peak-rate year may be detected because of the joint effects of scarcity, structural changes such as innovations, and changes in regulation in various regions. The interaction pattern cannot be inferred directly from the data. Fourth, while this study focuses on peak-rate year at the global level, a regional specific analysis may provide a different picture and more specific information on regional action.

\section{Cited literature}

Gasser T., H.-G. Müller, W. Köhler, L. Molinari, and A. Prader. 1984. Nonparametric regression analysis of growth curves. The Annals of Statistics 12: 210-229.

Haugh, L. D. 1976. Checking the independence of two covariance stationary time series: A univariate residual cross-correlation approach. Journal of the American Statistical Association 71(354): 378-384.

Miecznikowski, J. C., A. Vexler, and A. Sheperd. 2013. dbEmpLikeGOF: an R package for nonparametric likelihood ratio tests for goodness-of-fit and two-sample comparisons based on sample entropy. Journal of Statistical Software 54(3): 1-19.

R Core Team. 2013. R: A language and environment for statistical computing. R Foundation for Statistical Computing. Vienna, Austria. 